\title{
A Non-Traded Good, Specific Factors and International Migration
}

\author{
ERIKO HIRAIWA and MAKOTO TAWADA
}

\author{
Nagoya University \\ Correspondence to: Makoto Tawada \\ School of Economics, Nagoya University, Furo-cho, Chikusa-ku, Nagoya 464-8601, JAPAN \\ E-Mail: mtawada@soec.nagoya-u.ac.jp
}

\section{Introduction}

Since Rivera-Batiz (1982) analyzed the effects of international labor migration on factor prices and country welfare, subsequent extensions have been made by Lundahl (1985), Diajic (1986), Quibria (1988), Tawada and Kondoh (1991) and Kondoh (1993). Their analyses are based on a twogood and two-factor small country model, where one good is assumed to be non-traded and the inflow and outflow of immigrants are considered to be a shift in labor endowment. They have argued an effect of a change in labor endowment on the factor and non-traded good prices, and on the country welfare.

As Goto (1993) pointed out, however, if we look into the actual labor movement in the host country a careful attention should be paid to the model building. He found that the foreign workers migrated to Japan, for example, had entered generally into the non-traded good sector and been employed in construction sites or service industry. ${ }^{1)}$ On the other hand if we turn our eyes to those countries that are sending emigrants to overseas, as Sassen (1988) argued, information from the outside countries through traded goods is deeply imbedded to the process of producing emigrants in the source countries. What we realize, therefore, is that the labor engaged in the traded good sector dominates the substantial proportion of workers who emigrate to the foreign countries. In this context, because the framework of the models treated so far are based upon the assumption that labor is mobile between sectors, it is neglected which sector produces emigrants in the source countries and which sector receives immigrants in the host countries. It may be argued, therefore, that the ambigu-

1) For instance, Goto (1993) reported that a number of male foreign workers in Japan were employed in the construction industry while a number of female guest workers were engaged in the service industry as restaurant waitpersons and hostesses who got their visas as so-called entertainer's classification. 
ity may lead to sort of a double ambiguity in the analysis and may not fully reflect the abovementioned reality.

Thus, in this paper, supposing labor to be sector-specific, we will make it clear in which sectors the international labor movement occurs. In the non-traded good sector of the host country, workers at construction sites and waitpersons or hostesses in the service industry are dominant jobs, where low-skilled workers from the foreign countries find their jobs. On the other hand in the traded good sector of the host country, firms need high-skilled workers, as they are competitive in the world market, so that the employees are likely to be high-skilled workers. A similar argument could be applied to the sending countries. While the low-skilled workers are employed in the non-traded good sector as is often referred to so-called an informal sector, skilled workers work for production in traded good sector. The skilled workers in the source countries have little possibility to get jobs in the traded good sector after immigration. Unlike the high-skilled workers in the host countries, they don't have enough skills. So they ended up being employed as low-skilled workers in the host countries.

Reflecting this reality, the model to be presented below accommodates two goods and three factors. Two goods are traded and non-traded goods. One of three factors is mobile between sectors, capital, and other two factors are assumed to be specific labor that is non-shiftable between sectors. Here our analysis is based on a small-country model and we shall take up a host country. We will see how an increase in the supply of the specific labor in the non-traded good sector, caused by an inflow of immigrants, has an effect on the factor prices, the non-traded good price and the welfare level of the host country. As the same analysis can be applied to the case of the source country, we shall not consider the case explicitly in this paper.

After presenting the basic model in Section 2, we shall analyze the effect of an increase in the supply of labor on the factor prices and the non-traded good price in the receiving country. In Section 3, we show the analysis how the welfare level is affected. Section 4 summarizes some of the major results obtained in this paper.

\section{Model}

Let there be a small open country that uses three factors for producing two goods. The goods are traded $\left(S_{T}\right)$ and non-traded $\left(S_{N}\right)$, the factors are capital $(K)$, labor specific to the production for the traded good $\left(L_{T}\right)$ and labor specific to the production for the non-traded good $\left(L_{N}\right)$. We assume that the levels of commodity outputs are determined by the following production functions, which are linearly homogeneous and concave:

$$
\begin{array}{ll}
S_{T}=F_{T}\left(L_{T}, K_{T}\right)=L_{T} f_{T}\left(k_{T}\right), & k_{T} \equiv K_{T} / L_{T} \\
S_{N}=F_{N}\left(L_{N}, K_{N}\right)=L_{N} f_{N}\left(k_{N}\right), & k_{N} \equiv K_{N} / L_{N}
\end{array}
$$

where $K_{T}$ and $K_{N}$ are the capital inputs for the production of the traded and non-traded goods, re- 
spectively.

Under the assumptions of perfect competition and full employment, we obtain the following six equations,

$$
\begin{gathered}
P_{N} \frac{\partial F_{N}}{\partial L_{N}}=w_{N}, \\
\frac{\partial F_{T}}{\partial L_{T}}=w_{T}, \\
P_{N} \frac{\partial F_{N}}{\partial K_{N}}=\frac{\partial F_{T}}{\partial K_{T}}=r, \\
L_{T}=L^{*}{ }_{T}, \\
L_{N}=L^{*}, \\
K_{T}+K_{N}=K^{*},
\end{gathered}
$$

where $P_{N}$ denotes the non-traded good price relative to the traded good price chosen to be the numeraire in this analysis, $w_{N}$ and $w_{T}$ are the wage rates of the specific labor employed in the nontraded and traded good sectors, respectively, $L_{T}^{*}$ and $L^{*}{ }_{N}$ are the amounts of industry-specific labor in the traded good and non-traded good sectors, respectively, and $K^{*}$ stands for the exogenously given supply of capital.

In the present two-good framework, market equilibrium condition of the non-traded good can be expressed as,

$$
D_{N}\left(P_{N}, Y\right)=S_{N}\left(P_{N}, L_{N}^{*}, L^{*}{ }_{T}, K^{*}\right),
$$

where $D_{N}\left(P_{N}, Y\right)$ and $S_{N}\left(P_{N}, L^{*}{ }_{N}, L^{*}{ }_{T}, K^{*}\right)$ are the demand function of the traded good and the supply function of the non-traded good, respectively, and $Y$ is the domestic aggregate income defined by

$$
Y=r K^{*}+w_{N} L_{N}^{*}+w_{T} L_{T}^{*} .
$$

From (3), (4) and (5), we obtain,

$$
\begin{aligned}
& P_{N}\left(f_{N}\left(k_{N}\right)-k_{N} f_{N}^{\prime}\left(k_{N}\right)\right)-w_{N}=0, \\
& f_{T}\left(k_{T}\right)-k_{T} f_{T}^{\prime}\left(k_{T}\right)-w_{T}=0, \\
& P_{N} f_{N}^{\prime}\left(k_{N}\right)-f_{T}^{\prime}\left(k_{T}\right)=0 .
\end{aligned}
$$

And by utilizing (6), (7) and (s), we have,

$$
k_{T} L_{T}^{*}+k_{N} L_{N}^{*}-K^{*}=0 \text {. }
$$

Then (9) can be rewritten from (10), (6) and (7) as

$$
D_{N}\left(P_{N}, r k^{*}+w_{T} L_{T}^{*}+w_{N} L_{N}^{*}\right)=S_{N}\left(P_{N}, L_{N}^{*}, L_{T}^{*}, K^{*}\right) \text {. }
$$

The equation system (11) - (15) determines $P_{N}, w_{N}, w_{T}, k_{N}$ and $k_{T}$ once $L^{*}{ }_{T}, L^{*}{ }_{N}$ and $K^{*}$ are given. Now, for the comparative static analysis discussed below, differentiating equations (15) and (11) (14), we obtain 


$$
\begin{aligned}
& {\left[\begin{array}{ccccc}
D_{N}^{P}-S_{N}^{P} & 0 & 0 & D_{N}^{Y} L^{*}{ }_{N} & D_{N}^{Y} L^{*}{ }_{T} \\
f_{N}-k_{N} f_{N}^{\prime} & -P_{N} f_{N}^{\prime \prime} k_{N} & 0 & -1 & 0 \\
0 & 0 & -f_{T}^{\prime \prime} k_{T} & 0 & -1 \\
f_{N}^{\prime} & P_{N} f_{N}^{\prime \prime} & -f_{T}^{\prime \prime} & 0 & 0 \\
0 & L^{*}{ }_{N} & L^{*}{ }_{T} & 0 & 0
\end{array}\right]\left[\begin{array}{l}
d P_{N} \\
d k_{N} \\
d k_{T} \\
d w_{N} \\
d w_{T}
\end{array}\right]} \\
& =\left[\begin{array}{c}
-D_{N}^{Y} w_{N}+S_{N}^{N} \\
0 \\
0 \\
0 \\
-k_{N}
\end{array}\right] d L^{*}+\left[\begin{array}{c}
-D_{N}^{Y} w_{T}+S_{N}^{T} \\
0 \\
0 \\
0 \\
-k_{T}
\end{array}\right] d L_{T}^{*},
\end{aligned}
$$

where $D_{N}^{P} \equiv \partial D_{N} / \partial P_{N}, D_{N}^{Y} \equiv \partial D_{N} / \partial Y, S_{N}^{N} \equiv \partial S_{N} / \partial L^{*}{ }_{N}, S_{N}^{T} \equiv \partial S_{N} / \partial L_{T}^{*}$ and $S_{N}^{P} \equiv \partial S_{N} / \partial P_{N}$.

Let us now consider the following Walrasian adjustment process in the non-traded good market:

$$
\dot{P}_{N}=\alpha\left(D_{N}\left(P_{N}, Y\right)-S_{N}\left(P_{N}, L_{N}^{*}, L_{T}^{*}, K^{*}\right)\right) .
$$

where equations (11) - (14) are assumed to be instantly adjusted and the parameter $\alpha$ is positive and constant and indicates an adjustment speed. As precisely shown in Tawada (1989, Appendix I), the sufficient condition for the stability of this dynamic mechanism is that $\left|J^{*}\right| /|J|<0$, where $|J|$ is the square matrix in (16) and $\left|J^{*}\right|$ is the co-factor of component $(1,1)$ of $|J|$.

Calculation of $\left|J^{*}\right|$ yields

$$
\begin{aligned}
& \left|J^{*}\right|=\left|\begin{array}{cccc}
-P_{N} f_{N}^{\prime \prime} k_{N} & 0 & -1 & 0 \\
0 & -f_{T}^{\prime \prime} k_{T} & 0 & -1 \\
0 & -f_{T}^{\prime \prime} & 0 & 0 \\
0 & L_{T}^{*} & 0 & 0
\end{array}\right|=(-1)\left|\begin{array}{ccc}
0 & -f_{T}^{\prime \prime} k_{T} & -1 \\
P_{N} f_{N}^{\prime \prime} & -f_{T}^{\prime \prime} & 0 \\
L_{N}^{*} & L_{T}^{*} & 0
\end{array}\right| \\
& =P_{N} f_{N}^{\prime \prime} L_{T}^{*}+L_{N}^{*} f_{N}^{\prime \prime}<0 .
\end{aligned}
$$

By applying this to the stability condition that $\left|J^{*}\right| /|J|<0$, we have $|J|>0$. Thus, throughout of our analysis, we employ the assumption that $|J|>0$.

\section{The Effects on Prices}

Now, we examine how the inflow of immigrants influences the prices of the related factors and non-traded good, when it raises the labor supply in the non-traded good sector. Then, based on this analysis, we shall proceed to discuss the impact of the inflow of foreign workers on the welfare of native residents.

The basic equation system is (16) for our analysis. Because our interest is focused on a change in $L^{*}{ }_{N}$, let us determine first the sign of $\alpha \equiv-D_{N}^{Y} w_{N}+S_{N}^{N}$ is (16). Since $S_{N}^{N}=w_{N} / P_{N}$, we have, 


$$
\alpha \equiv \frac{w_{N}}{P_{N}}\left(1-P_{N} D_{N}^{Y}\right)
$$

Assuming that the both of the traded and non-traded goods are normal goods, it can be verified that $\left(1-P_{N} D_{N}^{Y}\right)>0$, then we obtain $\alpha>0$.

From (16), considering that $|J|>0$ and $\alpha>0$, we have

$$
\frac{d P_{N}}{d L_{N}^{*}}=\left[\alpha\left(P_{N} f_{N}^{\prime \prime} L_{T}^{*}+f_{T}^{\prime \prime} L_{N}^{*}\right)-D_{N}^{Y} P_{N} f_{N}^{\prime \prime} f_{T}^{\prime \prime} k_{N} K^{*}\right] /|J|<0
$$

And also we can obtain,

$$
\begin{aligned}
\frac{d w_{N}}{d L^{*}{ }_{N}}=\left[\left(D_{N}^{P}-S_{N}^{P}\right) P_{N} f_{N}^{\prime \prime} k_{N}^{2} f_{T}^{\prime \prime}\right. & \\
+\alpha\left\{( f _ { N } - k _ { N } f _ { N } ^ { \prime } ) \left(L_{N}^{*} f_{N}^{\prime \prime}\right.\right. & \left.\left.+P_{N} f_{N}^{\prime \prime} L^{*}{ }_{T}\right)+f_{N}^{\prime} P_{N} f_{N}^{\prime \prime} L_{T}^{*}\right\} \\
& \left.\quad-P_{N} D_{N}^{Y} L^{*}{ }_{T} k_{N} k_{T} f_{N}^{\prime \prime} f_{T}^{\prime \prime} f_{N}\right] / J \mid<0 .
\end{aligned}
$$

Then, from the equation (19), we can derive the following conclusion.

\section{Theorem 1}

An increase in the supply of labor in the non-traded good sector caused by the immigrant inflow will reduce the levels of the price of the non-traded good and the wage rate of labor specific to the non-traded good production.

Next, let us examine the impact of a change in $L^{*}{ }_{N}$ on $w_{T}$ and $r$. The equation system (16) yields,

$$
\frac{d k_{T}}{d L^{*}{ }_{N}}=\left[-\left(D_{N}^{P}-S_{N}^{P}\right) P_{N} f_{N}^{\prime \prime} k_{N}+\alpha f_{N}^{\prime} L_{N}^{*}-D_{N}^{Y} L_{N}^{*} k_{N} P_{N} f_{N}^{\prime \prime} f_{N}\right] /|J|
$$

In view of the Slutsky Equation, we have

$$
D_{N}^{P}=\left.D_{N}^{P}\right|_{U=\bar{U}}-D_{N} D_{N}^{Y}=\left.D_{N}^{P}\right|_{U=\bar{U}}-f_{N} L_{N}^{*} D_{N}^{Y}
$$

so that (20) can be rewritten as

$$
\frac{d k_{T}}{d L^{*}{ }_{N}}=\left[-P_{N} f_{N}^{\prime \prime} k_{N}\left(\left.D_{N}^{P}\right|_{U=\bar{U}}-S_{N}^{P}\right)+\alpha f_{N}^{\prime} L_{N}^{*}\right] /|J|,
$$

where $\left.D_{N}^{P}\right|_{U=\bar{U}}$ shows a response of the demand for the non-traded good to a change in the relative price of the non-traded good when the utility level is kept constant.

As to (21), while the first term in the brackets of the right-hand side must be negative, the second term is positive so that the sign is ambiguous. If a net substitution effect of the non-traded good with respect to its relative price is sufficiently high (low) in consumption or (and) in production, then the first (second) term in the brackets of the right-hand side tends to become dominant so that we can alternatively state that $d k_{T} / d L^{*}{ }_{N}<0(>0)$.

Now we shall examine the case where $d k_{T} / d L^{*}{ }_{N}<0$. From the fact that $r=f_{T}^{\prime}\left(k_{T}\right)$, we have $d r /$ $d L_{N}^{*}>0$ since $d r l d L_{N}^{*}=f_{T}^{\prime \prime}\left(d k_{T} / d L_{N}^{*}\right)$. A reduction in $k_{T}$ means a reduction in $k_{T}$. That leads to an increase in $K_{N}$. Thus, it shows that an inflow of labor to the non-traded good sector inevitably 
accompanies a draw of capital from the traded good sector as a complement to the labor inflow. As a result, the output of the non-traded good expands. This happens because the demand or the supply for the non-traded good is responsive to the decline of the relative price of the traded good. As regards the wage rate in the traded good sector, from the fact that $w_{T}=f_{T}-k_{T} f_{T}^{\prime}$, we obtain $d w_{T} / d L^{*}{ }_{N}$ $=-k_{T} f_{T}^{\prime \prime}\left(d k_{T} / d L_{N}^{*}\right)<0$.

On the other hand, in the case where $d k_{T} / d L^{*}{ }_{N}<0$, neither the demand nor supply for the nontraded good is sufficiently responsive to a decline in the relative price of the non-traded good. Then, the non-traded good sector may respond to an increase in $L^{*}{ }_{N}$ by substituting labor with capital. This suggests that $K_{T}$ tends to increase and $K_{N}$ tends to decrease, so that $d r / d L^{*}{ }_{N}<0, d w_{T} / d L^{*}{ }_{N}>0$.

The following conclusions then emerge from this argument.

\section{Theorem 2}

i) Assume that the substitution effect of the demand or supply for the non-traded good with respect to a change in the relative price of that good is large enough, then an increase in the labor inflow from foreign countries will raise the level of the rental on capital and will reduce the wage rate on labor specific to the traded good. This implies that, as the relative portion of capital shifts to the traded good sector from the non-traded, the output level of the non-traded good increases and the output level of the traded good contracts.

ii) Assume that the substitution effects of both demand and supply for the non-traded good with respect to a change in the relative price of that good are small enough. Then an increase in the labor inflow from foreign countries will reduce the level of the rental on capital and raise the wage rate on labor specific to the traded good. This implies that, as the relative portion capital shifts to the traded good sector from the non-traded, the output level of not only the traded good sector but also the nontraded good expands.

\section{The Welfare Analysis}

Now we examine the impact of the labor inflow on the level of welfare in the host country. Here in this paper, the level of welfare in the host country is assumed to be the level of aggregate utility of the capital owners and the native workers excluding the immigrant workers ${ }^{2)}$. Introducing $Y_{d}$, gross domestic income excluding the income of immigrant workers, it can be expressed as

$$
Y_{d}=w_{N} L_{N}^{d}+w_{T} L_{T}^{*}+r K^{*},
$$

where $L_{N}^{d}\left(\leq L^{*}{ }_{N}\right)$ denotes the allover specific labor supply in the non-traded sector excluding the immigrant labor supply, that is, the given supply of the native labor. Differentiating this equation totally by setting the levels of $L_{N}^{d}, L^{*}{ }_{T}$ and $K^{*}$ are constant, we obtain

2) We suppose that capital owners and workers specific to the traded good sector are all native. 


$$
d Y_{d}=L_{N}^{d} d w_{N}+L_{T}^{*} d w_{T}+K^{*} d r .
$$

Since $w_{T}=f_{T}-k_{T} f_{T}^{\prime}$ and $r=f_{T}^{\prime}$, we obtain $w_{T}=-k_{T} f_{T}^{\prime \prime} d r$. Hence (22) can be expressed as

$$
d Y_{d}=L_{N}^{d} d w_{N}+K_{N} d r .
$$

Now we introduce an indirect utility function, $V\left(P_{N}, Y_{d}\right)$, representing the aggregate utility of the capital owners and native workers excluding the immigrants. Then by (23) and Roy's Identity, we derive

$$
d V=V^{y}\left(-D_{N d} d P_{N}+L_{N}^{d} d w_{N}+K_{N} d r\right),
$$

where $V^{y} \equiv \partial V / \partial Y_{d}, D_{N d}$ denotes the quantity of the non-traded good demanded by the owners of the income $Y_{d}$.

Next, let $L_{N}^{m}$ be the amount of immigrant labor, so that $L^{*}{ }_{N}=L_{N}^{m}+L_{N}^{d}$. Then we obtain $P_{N} S_{N}=$ $w_{N} L_{N}^{m}+w_{N} L_{N}^{d}+r K_{N}$. By differentiating this totally, we have

$$
L_{N}^{d} d w_{N}+K_{N} d r=P_{N} d S_{N}+S_{N} d P_{N}-w_{N} d L_{N}^{m}-L_{N}^{m} d w_{N}-r d K_{N}
$$

Furthermore, making use of (2), (3) and (5) yields

$$
P_{N} d S_{N}=w_{N} d L_{N}^{m}+r d K_{N} \text {. }
$$

Thus we have

$$
L_{N}^{d} d w_{N}+K_{N} d r=S_{N} d P_{N}-L_{N}^{m} d w_{N} .
$$

Substituting these terms into (23), we obtain

$$
\begin{aligned}
\frac{d V}{d L^{*}{ }_{N}} & =V^{y}\left(\left(-D_{N d}+S_{N}\right) \frac{d P_{N}}{d L^{*}{ }_{N}}-L_{N}^{m} \frac{d w_{N}}{d L^{*}{ }_{N}}\right) \\
& =V^{y}\left(D_{N m} \frac{d P_{N}}{d L^{*}{ }_{N}}-L_{N}^{m} \frac{d w_{N}}{d L^{*}{ }_{N}}\right),
\end{aligned}
$$

where the expression $D_{N m}=D_{N}-D_{N d}$ denotes the quantity of the non-traded good demanded by the immigrant workers.

The income constraint of the immigrant workers can be shown as $P_{N} D_{N m}+D_{T m}=w_{N} L_{N}^{m}$, where $D_{T m}$ denotes the quantity of the traded good demanded by the immigrant workers. Thus, we have

$$
D_{N m} \frac{d P_{N}}{d L^{*}{ }_{N}}-L_{N}^{m} \frac{d w_{N}}{d L^{*}{ }_{N}}=\frac{P_{N}}{w_{N}} D_{N m}\left(\frac{w_{N}}{P_{N}} \frac{d P_{N}}{d L^{*}{ }_{N}}-\frac{d w_{N}}{d L^{*}{ }_{N}}\right)-\frac{D_{T m}}{w_{N}} \frac{d w_{N}}{d L^{*}{ }_{N}} .
$$

Furthermore, from (18) and (19), we also have

$$
\begin{aligned}
& \frac{w_{N}}{P_{N}} \frac{d P_{N}}{d L^{*}{ }_{N}}-\frac{d w_{N}}{d L^{*}{ }_{N}} \\
& =\left[\left(-K_{N} f_{N}+k_{N} f_{N}^{\prime} K^{*}\right) P_{N} D_{N}^{Y} f_{N}^{\prime \prime} f_{T}^{\prime \prime} k_{N}-\left\{\left(D_{N}^{P}-S_{N}^{P}\right) k_{N} f_{T}^{\prime \prime}+\alpha f_{N}^{\prime} L_{T}^{*}\right\} P_{N} f_{N}^{\prime \prime} k_{N}\right] /|J| \\
& =\left[k_{N}\left(r K_{T}-w_{N} L_{N}\right) D_{N}^{Y} f_{N}^{\prime \prime} f_{T}^{\prime \prime} k_{N}-\left\{\left(D_{N}^{P}-S_{N}^{P}\right) k_{N} f_{T}^{\prime \prime}+\alpha f_{N}^{\prime} L_{T}^{*}\right\} P_{N} f_{N}^{\prime \prime} k_{N}\right] /|J| .
\end{aligned}
$$

Assuming that $r K_{T} \geq w_{N} L_{N}$, we can observe that (27) is positive. Tnus, it is verified that (26) is 
positive. From (25), therefore, $d V / d L^{*}{ }_{N}>0$.

When the magnitude of demand or supply substitution of the non-traded good with respect to a change in its relative price is sufficiently large, we have $d r / d L^{*}{ }_{N}>0$. Then, by assuming $L_{N}^{m}$ to be small and $L_{N}^{d}$ to be large in order that $L^{*}{ }_{N}$ be left unchanged, the values of $d w_{N} / d L^{*}{ }_{N}$ and $d r / d L^{*}{ }_{N}$ tend to be less influenced. Thus, we can conclude that $L_{N}^{d}\left(d w_{N} / d L^{*}{ }_{N}\right)+K_{N}\left(d r / d L^{*}{ }_{N}\right)>0$, for sufficiently small $L_{N}^{d}$. Therefore, in view of (24), we can obtain $d V / d L^{*}{ }_{N}>0$.

Now, we have the following conclusions.

\section{Theorem 3}

i) If the payment for over-all capital in the traded good sector is equal to or larger than the payment for the over-all labor in the non-traded good sector, an inflow of immigrant workers raises the welfare of the native residents.

ii) If the magnitude of the demand or supply substitution of the non-traded good for the traded with respect to a change in the relative price of the non-traded good is sufficiently large, and the initial endowment of the native labor in the non-traded good sector is sufficiently small, an inflow of immigrant workers can raise the welfare of the native residents.

\section{Conclusion}

Now let us compare the results we have obtained in this paper with the case where labor is mobile between sectors. Tawada and Kondoh (1991) have analyzed the case where labor is intersectorally mobile in the host country. They showed that whether an increase in the supply of immigrant workers raises or reduces the price of the non-traded good depends on factor intensity in the non-traded good sector. If the non-traded good sector is assumed to be capital-intensive (laborintensive), then the price of the non-traded good rises (declines). Foreign workers flow into the labor-intensive sector in general. Therefore, if the non-traded good sector is capital-intensive (labor-intensive), the labor supply in the traded good sector (non-traded good sector) increases and then the output level of the traded good sector (non-traded good sector) will relatively increase. On the other hand, in this paper, as immigrant workers are assumed to flow only into the non-traded good sector, the increase in the immigrant workers win expand the output of the non-traded good and then lower its price.

In Tawada and Kondon's model (1991), an increase in the immigrant labor inflow lowers the wage rate and raises the rental on capital. This is because the overall labor endowment in the host country increases. In this paper, however, while the wage rate of the non-traded good sector declines, the rental on capital has both possibilities in its change; it could decline or rise. Since the capital shifts from the traded good sector (non-traded good sector) to the non-traded good sector (traded good sector) if labor and capital are complementary (substitute) in the non-traded sector, the 
rental on capital results in a rise (decline) through a change in the capital-labor ratio in the traded good sector. And the wage rate of labor specific to the traded good will decline (rise).

As for the effect of the immigrants' inflow to the host country on the welfare of native residents excluding the immigrants, it is rather complicated compared to its impact on the factor prices. Tawada and Kondoh (1991) have shown the result that the welfare rises if the non-traded good sector is capital-intensive. In this paper, however, we have shown that the welfare of the native residents rises under restrictive conditions as argued in the Theorem 3. Therefore, we need a further investigation on the welfare aspect to generalize the result.

What remains to be explored might be an analysis focused on a sending country of immigrants as well as on a case where immigrants' remittance to their home countries exists. Furthermore, of another interest would be the analysis of a case where the workers in the non-traded good sector have an opportunity to move to the traded good sector after acquiring certain skin training. These are the future tasks we have to tackle.

\section{References}

Diajic, S., 1986, International Migration, Remittances and Welfare in a Development Economy, Journal of Development Economics, vol. 21, 229-234.

Goto, J., 1993, Foreign Workers and Economy in Japan-In view of Migro-Economics (in Japanese), Yuhikaku Press.

Kondoh, K., 1993, An Analysis on the Economic Behavior of Illegal Migrants (in Japanese), Oikonomica, vol. 30, 99-108.

Lundahl, M., 1985, International Migration, Remittances and Real Incomes: Effects on the Source Country, Scandinavian Journal of Economics, vol. 87, 647-657.

Quibria, M.G., 1998, A Note on International Migration, Non-Traded Goods and Economic Welfare in the Source Country, Journal of Development Economics, vol. 28, 377-387.

Rivera-Batiz, F., 1982, International Migration, No-Traded Goods and Economic Welfare in the Source Country, Journal of Development Economics, vol. 11, 81-90.

Ssassen, S., 1998, The Mobility of Labor and Capital: A Study in International Investment and Labor Flows, Cambridge University Press.

Tawada, M., 1989, Production Structure and International Trade, Springer-Verlag.

Tawada, M, and K. Kondoh, 1991, The Economic Analysis on a Host Country of Immigration with Remittance, Studies in Regional Science, vol. 21, no. 2, 35-45. 